\title{
Interface conditions and code-switching: Pronouns, lexical DPs, and checking theory
}

\author{
Elly van Gelderen, Jeff MacSwan *,1 \\ Arizona State University, Tempe, AZ 85297, United States
}

Received 15 March 2006; received in revised form 3 April 2007; accepted 16 May 2007

Available online 6 July 2007

\begin{abstract}
The ban on code-switching between a (subject) pronoun and a verb, but not between a lexical DP and a verb, is an enduring puzzle in research on bilingual code-switching. In this paper, we propose an account of these code-switching facts by positing that pronouns and lexical DPs take advantage of different checking strategies: While lexical DPs check features in [Spec, TP], pronouns undergo D-to-T movement. In the latter case, a mixed-language complex head results, a construction which crashes at PF, as predicted by the PF Disjunction Theorem.
\end{abstract}

(C) 2007 Elsevier B.V. All rights reserved.

Keywords: Minimalism; Code-switching; Pronoun; Head; Phrase; Interface; Coordination; Features

\section{Introduction}

The ban on code-switching between a (subject) pronoun and a verb, but not between a lexical DP and a verb, is an enduring puzzle in research on bilingual code-switching. In this paper, we propose an account of these code-switching facts by positing that pronouns and lexical DPs take advantage of different checking strategies: While lexical DPs check features in $[\mathrm{Spec}, \mathrm{TP}]$, pronouns undergo D-to-T movement. In the latter case, a mixed-language

\footnotetext{
* Corresponding author. Tel.: +1 4809654967.

E-mail address: macswan@asu.edu (J. MacSwan).

${ }^{1}$ Both authors are affiliated with Arizona State University; in fall of 2004, Elly van Gelderen was a Fellow at the Centre for Advanced Study in Oslo, and Jeff MacSwan was a Visiting Scholar in the MIT Linguistics Department.
} 
complex head results, a construction which crashes at PF, as predicted by the PF Disjunction Theorem.

This paper is organized as follows. First we outline the Minimalist Program, which forms the general theoretical framework of our analysis. We then sketch MacSwan's (1999) Minimalist approach to code-switching. We follow with a short review of the status of pronouns and lexical DPs in current linguistic theory and its relation to the theory of movement. We present our analysis after briefly reviewing the literature on pronoun-verb codeswitches.

\section{The Minimalist Program}

In the Minimalist Program (Chomsky, 1995, 2001a, 2001b), all parameters are encoded in the lexicon, with the consequence that linguistic variation falls out from the morphological properties (abstract and concrete) of the lexical items (Borer, 1984). In this model, there are two central components: a computational system for human language, which is presumed to be invariant across languages, and a lexicon, to which the idiosyncratic differences observed across languages are attributed.

Phrase structure is also derived from the lexicon in the Minimalist Program. An operation, called Select, picks items from the lexicon and introduces them into the lexical array, an assembled subset of the lexicon used to construct a derivation. Another operation, Merge, takes items from this array and forms new, hierarchically arranged syntactic objects (substructures). The operation Move (or Internal Merge, in Chomsky, 2001b) will be discussed further below. It applies to properties of objects formed by Merge to build new structures. In the Minimalist Program, then, structures are built derivationally by the application of the three operations Select, Merge and Move, constrained only by the condition that lexically encoded features match in the course of a derivation. The result of the derivation will be a Phonological Form (PF) and an Logical Form (LF), both interface levels.

Movements are driven by feature checking, and may be of two types. A head may undergo head movement and adjoin to another head, or a maximal projection may move to the specifier position of a phrase. There are several types of features: semantic (e.g. abstract object), phonological (e.g. the sounds), and formal (Chomsky, 1995:230ff, 236, 277ff). The formal ones are relevant to syntax and are divided into intrinsic or optional; and into interpretable or uninterpretable. The intrinsic ones are "listed explicitly in the lexical entry or strictly determined by properties so listed" (Chomsky, 1995:231) and include categorial features, the Case assigning features of the verb, and the person and gender features of the noun. Optional features are added arbitrarily and are predictable from Principles of UG (e.g. nouns need Case). They include the tense and agreement features of verbs and the number and Case features of NPs. The EPP feature (or Extended Projection Principle) ensures that subjects move to the specifier of TP.

Uninterpretable features trigger movement but interpretable ones do not. Interpretable features are relevant at LF and do not erase or delete but can be "used over." Uninterpretable features explain several phenomena earlier treated as separate. For instance, (a) a DP has one and only one uninterpretable Case feature, as (1) illustrates, and (b) the features justify the inclusion of functional categories in the lexical array and the ensuing movement into the heads and specifiers of these projections:

*Zoya ${ }_{\mathrm{i}}$ seemed $t_{i}$ was annoyed with Amir. 
In (1), Zoya cannot check the Case in both subject positions, an indication that Case is uninterpretable. ${ }^{2}$

In the generative framework, movement has always been seen as puzzling. As Chomsky (1998b:42) puts it, "[w]hy language should have this [movement] property is an interesting question, which has been discussed for almost 40 years without resolution." Verbal agreement and Case are problematic as well since they are not relevant to the interpretation in Modern English. Chomsky (1998a:42-48) proposes to connect both of these problems: The "offending" uninterpretable Case and agreement are eliminated through movement.

In short, we assume that linguistic expressions have a phonetic and a semantic component. In the ideal case, all features would be relevant at either LF or PF. This is, however, not true since there are features that force movement that are neither interpreted at the semantic nor at the phonetic interface; these features are uninterpretable, and include Case, agreement, and EPP. van Gelderen (2000) proposes that languages and different stages of the same language differ as to which features are interpretable. This analysis may be useful in explaining a number of codeswitching phenomena as well, but will not be crucial to the success of our analysis of the pronominal data. We will instead use the distinction between heads and maximal projections but first we outline a theory of code-switching consistent with the Minimalist Program.

\section{A Minimalist Approach to code-switching}

If all syntactic variation is associated with the lexicon, as in the Minimalist Program, then code-switching may be seen as the simple consequence of mixing items from multiple lexicons in the course of a derivation. MacSwan $(1999,2000)$ develops a model of intrasentential codeswitching in which items may be drawn from the lexicon of multiple (discretely represented) languages (two, in the simple case) to introduce features into the lexical array, which must then be checked for convergence in just the same way as monolingual features must be checked, with no special mechanisms permitted. The requirements are simply carried along with the lexical items of the respective systems. On this view, the relevant theory of code-switching is stated as in (2):

(2) Nothing constrains code-switching apart from the requirements of the mixed grammars.

Nothing constrains code-switching apart from the requirements of the mixed grammars. Note that (2) is a theory of code-switching, and not part of the theory of grammar. Indeed, (2) implies that no rule or principle of grammar may make explicit reference to code-switching, nor to the identities of particular languages. ${ }^{3}$

The phonological component, responsible for mapping the lexical array to PF, is of a very different character from the syntax. Phonological rules build structure in a way that syntax does not, and in doing so they often refer to specific morphological material with its phonetic content. Chomsky (1995) and others have pointed out that the mapping to the phonetic form is very different from the syntactic component of the grammar. Thus, while syntactic operations may apply at any time, operations of the phonological component must apply in a particular order, as Bromberger and Halle (1989) have also pointed out.

\footnotetext{
${ }^{2}$ In more recent work, there are a few changes, e.g. Chomsky (2001b), where movement in the narrow syntax (i.e. before PF and LF split) is restricted to phrases (e.g. subject DPs) and triggered by the EPP (or OCC) features of T. In this approach, head movement is phonological, an assumption consistent with the PF Disjunction Theorem.

${ }^{3}$ By "mixed grammars" we do not refer to grammars, each of which is mixed, but rather to discrete grammars which are mixed under conditions of code-switching.
} 
Notice that if we attempt to take the union of two PF components for the purposes of codeswitching, the ordering relations among rules will not be preserved. If, for instance, $\mathrm{L}_{\mathrm{X}}$ orders $\mathrm{R} 1$ before $\mathrm{R} 2$, and $\mathrm{L}_{\mathrm{Y}}$ orders $\mathrm{R} 2$ before $\mathrm{R} 1$, then the resulting system will have no ordering relations on R1 or R2, and it will fail to meet its requirement that rules be (partially) ordered with respect to one another. Rather than invoke a control structure which allows the systems to interface, it may be worthwhile to pursue the hypothesis, developed in MacSwan (1999), that code-switching in the computation $\mathrm{N} \rightarrow \pi$ is simply impossible, as expressed as in (3).

PF Disjunction Theorem

(i) The PF component consists of rules/constraints which must be (partially) ordered/ranked with respect to each other, and these orders/rankings vary cross-linguistically.

(ii) Code-switching entails the union of at least two (lexically-encoded) grammars.

(iii) Ordering relations are not preserved under union.

Therefore, code-switching within a PF component is not possible.

We take (3) to be an instantiation of Full Interpretation (FI), the requirement that every object have a sensorimotor interpretation to qualify as a legitimate representation. Since phonological systems cannot be mixed, code-switching at PF generates "unpronounceable" elements which violate FI. Notice that this system predicts that code-switching below $\mathrm{X}^{0}$ is not permitted, since $\mathrm{X}^{0} \mathrm{~s}$ are inputs to PF (Chomsky, 1995); indeed, there is some evidence that head movement falls quite generally within the phonological component rather than the narrow syntax, as Chomsky (2000:146, 2001a:37) has recently suggested. Thus, we assume that all $\mathrm{X}^{0} \mathrm{~s}$ must be phonologically parsed, and that phonological systems may be switched at word boundaries but not within words (heads). ${ }^{4}$

It is important to note, too, that (3), like (2), does not have the character of a constraint on codeswitching; (3) is a theory about the relationship between the phonological components of a bilingual's linguistic system, and is deduced from the nature of the phonological rules. Similarly, the lexicons are each language-specific for reasons that are independent of phenomena under analysis: Language-particular morphological rules of word formation apply to a discrete subset of the lexical items known to a bilingual, and those items uniquely qualify for PF interpretation by a language-particular phonological system. For reasons noted, phonological systems cannot be mixed, and this property has the effect of creating discrete lexicons for the languages known to a bilingual person. See MacSwan (1999, 2000) for an elaboration of empirical consequences of these ideas.

\section{Pronouns, lexical DPs, and movement}

A number of persuasive arguments have been advanced in which pronouns are analyzed as heads rather than phrases (Abney, 1987; Longobardi, 1994; Cardinaletti, 1994; Cardinaletti and Starke, 1996; Carnie, 2000), as had been traditionally assumed. While there has been some controversy over whether pronouns are base-generated under $\mathrm{D}$ or under $\mathrm{N}$, recent proposals analyze these structures as involving N-to-D movement internally within the DP, along lines pursued in Longobardi (1994).

\footnotetext{
${ }^{4}$ Grosjean and Miller (1994) provide phonetic evidence that code-switching between words is "complete," with no perseverative phonetic effects from one language into the other. However, phonological aspects of code-switching are dramatically under-investigated, and much more must be learned to illuminate the precise nature of the restriction noted.
} 
Subject pronouns might potentially check features with T either by head movement, as in (4a), or by moving into the specifier of $\mathrm{T}$, as in (4b).
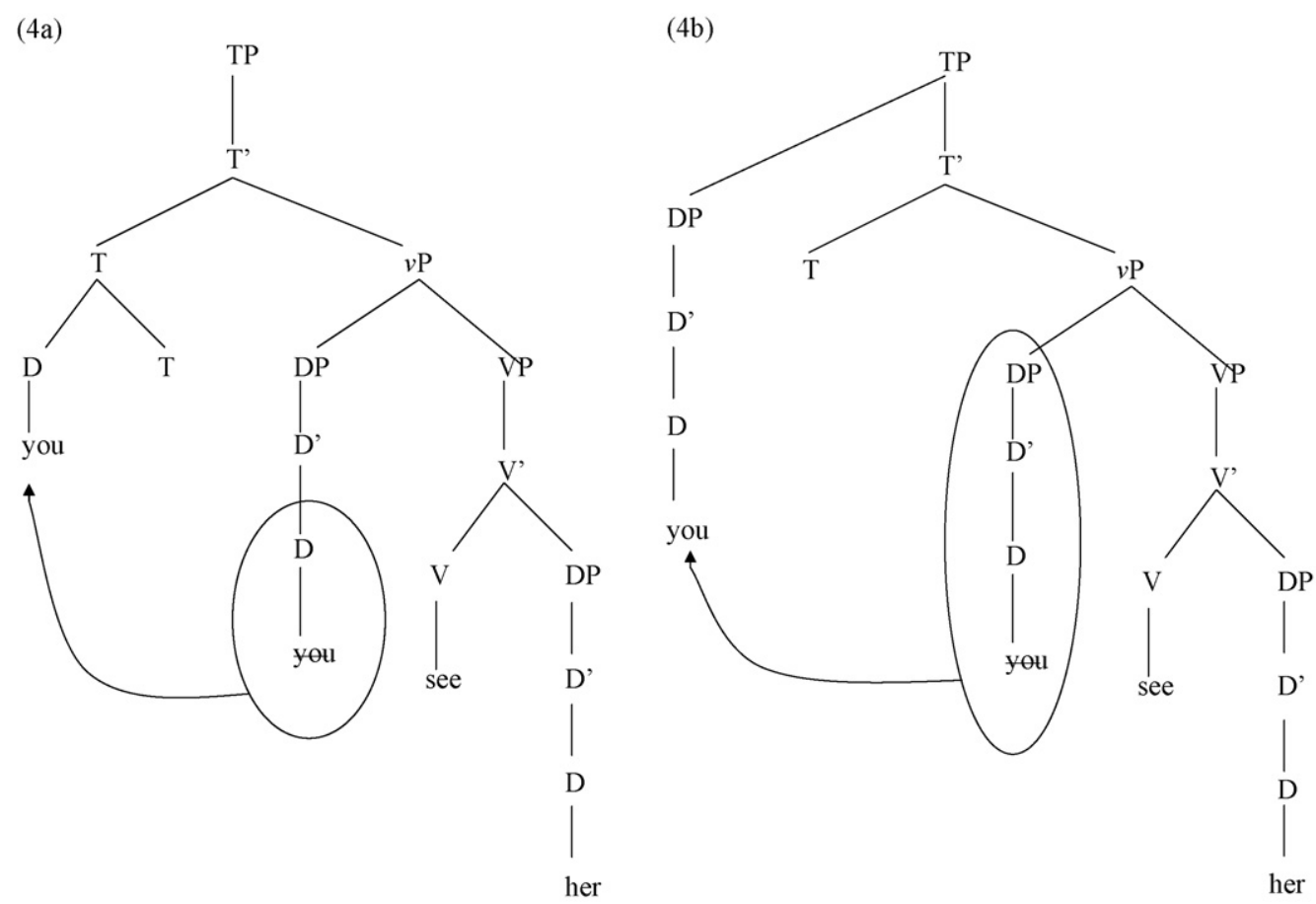

We will argue that, unlike pronouns, nouns do not have the option to be constructed as a head. Nouns, if they are to be argumental, have to have a $\mathrm{D}$ (eterminer). Pure NPs occur as predicates, vocatives, and adverbials, but not as subjects or objects (Higginbotham, 1985; Rothstein, 1983; Longobardi, 1994). This is the reason why most researchers assume a $\mathrm{D}$ even in languages that do not have an overt one. Thus, comparing pronouns and nouns given in $(5 \mathrm{a}, \mathrm{b})$ :

(5) a.<smiles>[2H][131I]</smiles>

b.<smiles>[2H][PH2]NC(C)=O</smiles>

When pronouns are coordinated or modified, they lose the ability to be heads. A structure for a coordinate pronoun is provided in (6). This is the stage in the derivation when the pronoun has just been combined with the coordinator and, and either the pronoun or the coordinator can project, i.e. the result can be a Coordinator Phrase (as in Munn, 1992; van Gelderen, 1997) or a DP, but never just a head:

(6)

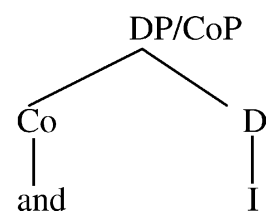


Evidence that pronouns move to head positions is provided by a number of independent facts. For instance, when pronouns are separated from the verb by an adverb, they are often repeated (in a corpus of American Spoken Professional English; see www.athel.com), as in (7) and (8), shown in van Gelderen (2004):

they apparently - they're involved in this

(White House briefings, 1996).

We find they, you know - they both work comfortably, to be honest with you (Commerce department meetings, 1997).

Repetition of subjects after and, as in (9), also occurs:

(9) Yes I do, and I am absolutely convinced ... (UNC Faculty Meetings, 1997)

In addition, pronouns are not generally modified, as in the with the green hair, a fact which follows from the assumption that they are heads.

Languages differ as to the lexical items they have in the lexicon. In English, we have seen that pronouns can function either as Ds or as heads of DPs. In colloquial French, only the head possibility is available for pronouns such as $j e$ ' $\mathrm{I}$ ' in (10):
Je le sais
I it know
'I know it'.

Since French pronouns are only heads, never phrases, coordinating pronouns is ungrammatical (e.g. *tu et je 'you and I'). There are special forms such as moi 'me', as in (11) that cannot check features but are used in most forms as a replacement of $j e$. We'll see in the next section that these two kinds function very differently:

$$
\begin{aligned}
& \text { Moi, je le sais } \\
& \text { me, I it know }
\end{aligned}
$$

Chomsky (1981:330) analyses pronominals as just $\phi$-features, with or without a phonological matrix:

Assume that there is some set of grammatical features $\phi$ that characterize pronouns; i.e., pronouns are distinguished from overt anaphors and R-expressions in that the grammatical features of pronouns are drawn solely from $\phi$, whereas overt anaphors and R-expressions have some other grammatical features as well. ... A pronominal has no grammatical features other than $\phi$-features, and may or may not have a phonological matrix.

The rich feature specification which is generally overtly encoded in the pronominal system leads one to suspect that they are base-generated under $\mathrm{D}$, and that an empty $\mathrm{N}$ moves to headadjoin to them. We will assume for concreteness that pronouns are base-generated under D and that an empty $\mathrm{N}$ moves to it for the purpose of checking its formal features. However, the only assumption here that is crucial to the success of our analysis below is the fairly uncontroversial claim that pronouns are heads which get to D (either through base-generation or movement). Thus, pronouns differ from lexical DPs only in that they contain (or are) a single phonetically realized head. 
In considering various pied-piping phenomena, Chomsky (1995:261-271) proposes a revision of Move $\alpha$ as Move F, a version of the movement operation which targets features (F) rather than lexical items. Move F would move formal features alone and strand their phonetic content, if not for the following economy principle which Chomsky further proposes:

F carries along just enough material for convergence.

Chomsky (1995:265) further assumes that "only PF convergence forces anything beyond features to raise." Features cannot exist on their own and therefore they need to pied pipe lexical material. Takahashi (2000), who explores the consequences of the Move F theory of movement for numerous Japanese phenomena, terms this requirement the PF Integrity Condition, defined in (13):

The PF Integrity Condition

Words whose features are isolated or scattered may not be subject to PF rules, making the derivation crash at PF.

As in the case of (3), (13) is understood as an instantiation of Full Interpretation.

Below we will argue for a version of (12): Move as little as you can. Pronouns can move as Ds and therefore do. Nominals cannot because, as argued above, if nouns are to be argumental, they have to have a $\mathrm{D}$ (eterminer) and a Noun which makes a full phrase. Pronounds, as Ds, do not have to project.

\section{Code-switching and pronouns}

\subsection{Previous analyses}

Timm (1975:477) observes, “[o]ne of the strongest restrictions against switching applies to pronominal subjects or objects ... and the finite verbs". This view is echoed by Gumperz (1976) and Lipski (1978). Although there are corpora of language pairs where different results obtain, there appears to be a robust finding in the code-switching literature that reveals a surprising fact: Whereas code-switching between a (subject) lexical DP and verb is well-formed, switching between a (subject) pronoun and a verb is ill-formed, as illustrated in (14) and (15) for English-Dutch.

$$
\begin{aligned}
& \text { The car talk brothers lachen altijd te veel } \\
& \text { The car talk brothers laugh always too much } \\
& \text { *They zeggen te veel } \\
& \text { They say too much }
\end{aligned}
$$

Working within the Matrix Language Frame (MLF) Model of Myers-Scotton (1993), Jake (1994) argues that there are at least four types of pronouns, to be divided along lexical/ grammatical lines consistent with Myers-Scotton's (1993) System-Morpheme Principle. On Myers-Scotton's (1993) view, "system morphemes which have grammatical relations external to their constituent ... will come from the ML" or matrix language (83). For Jake, examples of lexical (or emphatic) pronouns that can codeswitch are French moi 'me' in (16) and Moroccan Arabic nta 'you' in (17):

moi dxlt

I went-in 
(17)

nta tu vas travailler

you you go work

(French-Moroccan Arabic, from Benathila and Davies, 1983:313)

In (17), the non-lexical French pronoun $t u$ is included as well, reinforcing the idea that the pronoun $n t a$ is really lexical and has interpretable features like a full DP.

The same occurs in Dutch/Moroccan Arabic code-switching, as Nortier (1990) has shown. In Maroccan Arabic, there are two kinds of pronouns: dependent clitics and independent pronouns. Code-switching only occurs between the latter and a Dutch verb, as in (18) and (19):

$$
\text { humaya vergelijken de mentaliteit met de islam }
$$

they compare the mentality with the islam

ana ik vind 't zo'n knuffeldiertje

I I find it such a cuddly toy

(Moroccan Arabic-Dutch, from Nortier, 1990:165-166)

MacSwan (1999) reports Spanish-Nahuatl data which are problematic for Jake's (1994) analysis. In (20)-(23), a switch between a Spanish pronoun and a Nahuatl verb may not occur for first or second person; however, third person switches, are well-formed:

*Yo nikoas tlakemetl

yo ni-k-koa-s tlake-me-tl

I 1S-3Os-buy-fut garment-pl-nsf

'I will buy clothes'

*Tú tikoas tlakemetl

tú ti-k-koa-s tlake-me-tl

you/sing 2S-3Os-buy-fut garment-pl-nsf

'You will buy clothes'
Él kikoas tlakemetl
él 0-ki-koa-s tlak-eme-tl
he 3S-3Os-buy-fut garment-pl-nsf
'He will buy clothes'
Ella kikoas tlakemetl
ella 0-ki-koa-s tlake-me-tl
'She will buy clothes'
she 3S-3Os-buy-fut garment-pl-nsf

In Jake's system, Spanish personal pronouns should be system morphemes because they are assigned to argument position. We therefore expect codeswitches involving these elements to be well-formed if and only if the matrix language contributes the pronoun. Regardless of which language is analyzed to be the matrix language in (20)-(23), a problem emerges for Jake's analysis: In some instances the constructions are well-formed, and in others they are ill-formed.

Nonetheless, while Jake (1994) provides a rich and fascinating review of code-switching data, it is clear that the Myers-Scotton's (1993) MLF Model will not help with respect to the data in (20)-(23). Other theoretical and empirical limitations of the model suggest that there is little hope of saving the analysis with further elaboration, as MacSwan (2005) has shown in detail. 


\subsection{Our analysis}

Our analysis takes advantage of the economy condition regulating movement and the PF Integrity Principle, stated in (12) and (13), repeated here:

(12) F carries along just enough material for convergence.

(13) The PF Integrity Condition

Words whose features are isolated or scattered may not be subject to PF rules, making the derivation crash at PF.

Consider first the contrast in (14) and (15) above, again repeated:

(14) Their brothers, lachen altijd te veel

The car talk brothers laugh always too much

(15) *They zeggen te veel

They say too much

In the case of (14), D cannot raise to T while leaving its NP complement. Hence, the entire DP enters into a checking relation with $\mathrm{T}$ by moving into the [Spec, TP] position, as in (24).

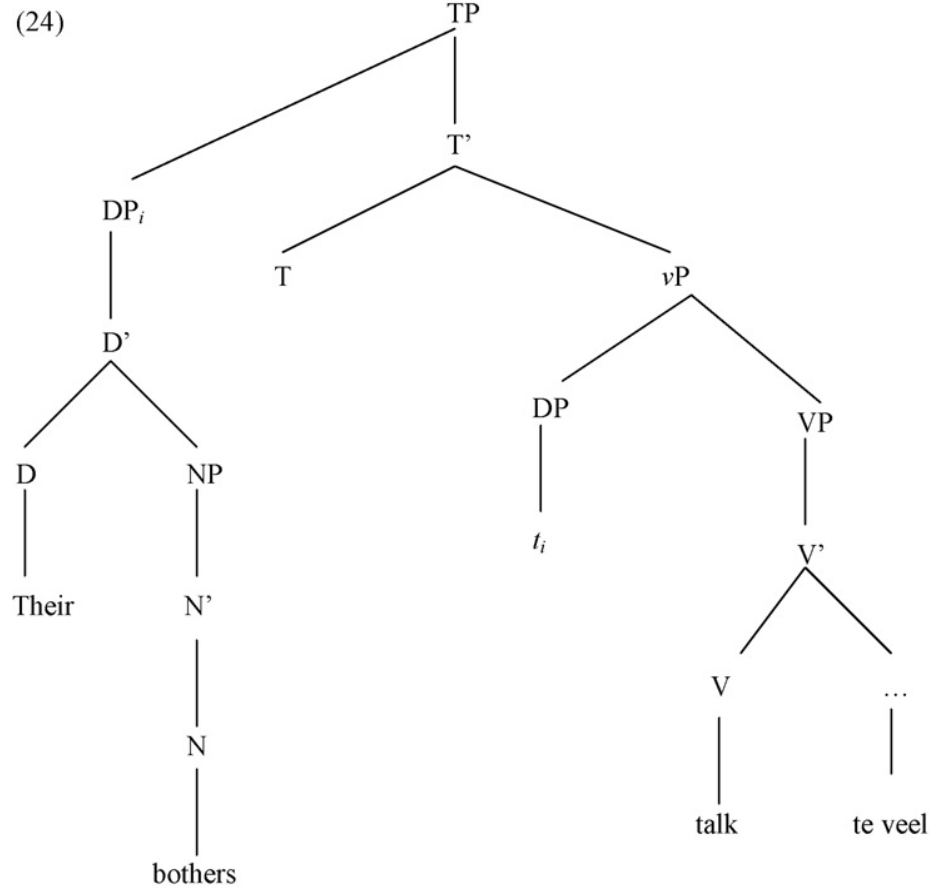

In (15), the pronoun is a head $\mathrm{D}$ which checks features with $\mathrm{T}$ by head-movement in an effort to satisfy the economy condition in (12). Because V also adjoins with $\mathrm{T}$ to value its features, the resulting structure is a complex head $\mathrm{T}$ which dominates a $\mathrm{V}$ zeggen and pronominal $\mathrm{D}$ they from 
two different languages. The PF Disjunction Theorem in (3), which rules out code-switching below X0, provides that the resulting construction will crash at PF.

Further support of the basic analysis we have presented also comes from some interesting coordination facts in Spanish-English code-switching. Consider the following ${ }^{5}$ :
a. *Yo fight all the time
I fight all the time
b. *Ellos fight all the time they fight all the time
c. *Ella fights all the time she fights all the time
a. Mi novia fights all the time
My girlfriend fights all the time
b. Mis amigos fight all the time
a. Mis amigos y yo fight all the time
My friends and I fight all the time
b. Yo y mis amigos fight all the time I and my friends all the time
c. Mis amigos y él fight all the time
My friends and he fight all the time
d. Mis amigos y ellos fight all the time
My friends and they fight all the time

Our consultants regarded all pronoun-verb switches to be ill-formed, as illustrated in (25), and found lexical DP-verb switches to be well-formed, as shown in (26). Our analysis predicts that coordinated structures such as those presented in (27) will behave like lexical DPs, since under coordinator feature checking may only be satisfied by XP movement, as attested.

However, a question arises. If a derivation is ill-formed because a pronoun moves to adjoin to $\mathrm{T}$, why can there not then be a successful derivation in which the full DP, which contains only a pronoun, moves into the specifier position of TP in order to successfully converge and avoid a mixed-language complex head? To resolve this, we invoke the Minimal Link Condition (MLC), which requires that features be checked by the shortest move possible (Chomsky, 1995:267-268). In the context of (12), the MLC means that F carries along just enough material for convergence but cannot "bypass" an opportunity to check its features with a shorter move.

This analysis successfully rules out code-switching between a pronoun and a verb. The analysis extends nicely to the cases in (16), (17) and (19), where the pronouns appear to be topicalized, and hence occupying a specifier position. We assume that the Arabic independent pronoun humaya in (18) has moved as a full DP into the subject position.

Finally, let us turn to an analysis of the data in (20)-(23), presented earlier as counterexamples to Jake's analysis within the MLF Model of Myers-Scotton (1993). The examples

\footnotetext{
${ }^{5}$ Grammaticality judgments obtained from two young adult Spanish-English bilinguals residing in Central Arizona who learned Spanish as infants and English in primary school.
} 
presented there illustrate that, in Spanish-Nahuatl code-switching, an asymmetry emerges: A codeswitch between a Spanish pronoun and a Nahuatl verb may not occur for first or second person, but third person switches are well-formed. Notice that the subject agreement morpheme is null for the third person in Nahuatl, but is $n i$-for first person and $t i$ - for second person, as may be observed in the examples given. This asymmetry in agreement affixes is parallel to what one finds in English, where $-s$ marks third-person agreement but the first and second person are null. Pollock (1994) has suggested that there is no null person suffix $-\varnothing$ which contrasts with $-s$ in English; that is, rather than claiming that English bare verbs have phonetically empty agreement affixes, Pollock argues that they have no agreement affixes at all, and that English verbs undergo feature checking only if they are marked with an agreement morpheme whose features require checking; otherwise the element remains in situ.

We might suggest, in parallel fashion, that Nahuatl null third person does not exist, and verbs do not enter into an agreement relation with $T$ to check features unless they are inflected with a subject agreement morpheme. A pronominal $\mathrm{D}$ may now raise to check features with $\mathrm{T}$ without ill-formedness resulting, as $\mathrm{T}$ has not entered into a checking relation with $\mathrm{V}$, and hence no head dominates heads lexically filled by more than one language. ${ }^{6}$

\section{Conclusion}

The ban on code-switching between a (subject) pronoun and a verb, but not between a lexical DP and a verb, has been an enduring puzzle in research on bilingual code-switching. We have proposed an analysis of the code-switching data which posits that pronouns and lexical DPs take advantage of different checking strategies: While lexical DPs check features in [Spec, TP], pronouns undergo D-to-T movement. In the latter case, the resulting formation is a mixedlanguage complex head, which therefore crashes at PF, as predicted by the PF Disjunction Theorem. In further work, we hope to pursue an analysis of possible counter-examples by examining possible differences in Case and interpretability of feature composition, along lines pursued in van Gelderen (2000).

\section{Acknowledgments}

Thanks to Andrew Carnie and Javier Gutierrez-Rexach for helpful comments, and to participants at the Third International Symposium on Bilingualism in Bristol, especially to Jürgen Meisel and Regina Köppe, who reacted to an earlier version of this paper.

\section{References}

Abney, S.P., 1987. The English noun phrase in its sentential aspect. Ph.D. Dissertation. MIT.

Borer, H., 1984. Parametric Syntax: Case Studies in Semitic and Romance Languages. Foris, Dordrecht.

Bromberger, S., Halle, M., 1989. Why phonology is different. Linguistic Inquiry 20, 51-70.

Cardinaletti, A., 1994. On the internal structure of pronominal DPs. Linguistic Review 11, 3-4, $195-219$.

Cardinaletti, A., Starke, M., 1996. Deficient pronouns: a view from Germanic. A study in the unified description of Germanic and Romance. In: Thrainsson, Hoskuldur, Epstein, Samuel David, Peter, Steve (Eds.), Studies in Comparative Germanic Syntax, vol. 2. Kluwer, Dordrecht, Netherlands, pp. 21-65.

\footnotetext{
${ }^{6}$ This analysis departs from MacSwan (2000) in which it is suggested that the first and second person cases in (20)-(23) are not convergent due to conflicts in the gender specifications of Spanish and Nahuatl.
} 
Carnie, A., 2000. On the definition of $\mathrm{X}^{0}$ and XP. Syntax 3 (2), 59-106.

Chomsky, N., 1981. Lectures on Government and Binding. Mouton de Gruyter, New York.

Chomsky, N., 1995. The Minimalist Program. MIT Press, Cambridge.

Chomsky, N., 1998a. Nuestro Conocimiento del Lenguaje Humano. Edicin bilinge. Impresos Universitaria, Santiago de Chile.

Chomsky, N., 1998b. Some observations on economy in generative grammar. In: Barbosa, P., Fox, D. (Eds.), Is the Best Good Enough? MIT Press, Cambridge, pp. 115-127.

Chomsky, N., 2000. Minimalist inquiries: the framework. In: Martin, R., Michaels, D., Uriagereka, J. (Eds.), Step by Step: Essays on Minimalist Syntax in Honor of Howard Lasnik. MIT Press, Cambridge.

Chomsky, N., 2001a. Derivation by phase. In: Kenstowics, M. (Ed.), Ken Hale: A Life in Language. MIT Press, Cambridge, pp. 1-51.

Chomsky, N., 2001b. Beyond Explanatory Adequacy. MITWPL.

Grosjean, F., Miller, J.L., 1994. Going in and out of languages: an example of bilingual flexibility. Psychological Science 5 (4), 201-206.

Gumperz, J., 1976. The sociolinguistic significance of conversational code-switching. Papers on Language and Context: Working Papers 46. Language Behavior Research Laboratory, University of California at Berkeley, pp. $1-46$.

Higginbotham, J., 1985. On semantics. Linguistic Inquiry 16, 547-593.

Jake, J., 1994. Intrasentential code-switching and pronouns: on the categorial status of functional elements. Linguistics 32 , 271-298.

Lipski, J., 1978. Code-switching and the problem of bilingual competence. In: Paradis, M. (Ed.), Aspects of Bilingualism. Hornbeam Press, Columbia, SC.

Longobardi, G., 1994. Reference and proper names: a theory of N-movement in syntax and logical form. Linguistic Inquiry 25 (4), 609-665.

MacSwan, J., 1999. A Minimalist Approach to Intrasentential Code Switching. New York, Garland.

MacSwan, J., 2000. The architecture of the bilingual language faculty: evidence from code-switching. Bilingualism: Language and Cognition 3 (1), 37-54.

MacSwan, J., 2005. Code-switching and generative grammar: a critique of the MLF Model and some remarks on "modified minimalism." Bilingualism: Language and Cognition 8 (1).

Munn, A., 1992. A null operator analysis of parasitic gaps. The Linguistic Review 9.1, 1-26.

Myers-Scotton, C., 1993. Dueling Languages: Grammatical Structure in Code-switching. Clarendon Press, Oxford.

Nortier, J., 1990. Dutch-Moroccan Arabic Code Switching. Foris, Dordrecht.

Pollock, J.-Y., 1994. Checking theory and bare verbs. In: Cinque, G., Koster, J., Pollock, J.-Y., Rizzi, L., Zanuttini, R. (Eds.), Paths Towards Universal Grammar: Studies in Honor of Richard S. Kayne. Georgetown University Press, Washington, DC.

Rothstein, S., 1983. The Syntactic Forms of Predication. MIT Diss.

Takahashi, D., 2000. Move F and raising of lexical and empty DPs. In: Martin, R., Michaels, D., Uriagereka, J. (Eds.), Step by Step: Essays on Minimalist Syntax in Honor of Howard Lasnik. MIT Press, Cambridge.

Timm, L.A., 1975. Spanish-English code-switching: El porqué and how-not-to. Romance Philology 28, $473-482$.

van Gelderen, E., 1997. Verbal Agreement and the Grammar Behind its 'Breakdown'. Niemeyer, Tübingen.

van Gelderen, E., 2000. A History of Reflexive Pronouns. John Benjamins, Amsterdam.

van Gelderen, E., 2004. Grammaticalization as Economy. John Benjamins, Amsterdam.

\section{Further reading}

MacSwan, J., 2004. Code switching and linguistic theory. In: Bhatia, T.K., Ritchie, W. (Eds.), Handbook of Bilingualism. Oxford, Blackwell. 